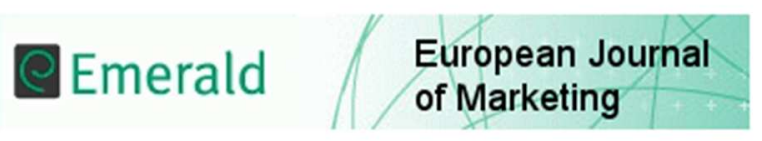

\title{
Validation and Sufficiency
}

\begin{tabular}{|r|l|}
\hline Journal: & European Journal of Marketing \\
\hline Manuscript ID & EJM-02-2016-0113 \\
\hline Manuscript Type: & Original Article \\
\hline Keywords: & $\begin{array}{l}\text { Agent-Based Modeling, ABM, Word of Mouth, Diffusion, Social Networks, } \\
\text { Modelling Assumptions }\end{array}$ \\
\hline \multicolumn{2}{|l}{} \\
\hline
\end{tabular}

\section{SCHOLARONE $^{\text {m }}$ \\ Manuscripts}




\title{
Validation and Sufficiency
}

We much appreciate the thoughtful commentaries of Nejad, and Rand and Rust on our paper "Improving Agent-Based Models of Diffusion" (East, Uncles, Romaniuk and Lomax, hereafter EURL). We believe this exchange will raise interest in the application of agentbased modeling $(\mathrm{ABM})$ to the diffusion of innovation and to applications in marketing more generally.

EURL argued that ABM was difficult to apply to the complexities of the diffusion of innovation and specifically targeted a much cited paper by Goldenberg, Libai, Moldovan, and Muller (2007, hereafter GLMM). The EURL criticism has two aspects. First, we suggest that studies made after publication of the paper cast doubt on the assumptions made by GLMM. Thus, we give substance to the need for the validation of assumptions that was emphasized by Rand and Rust (2011). Second, we argue that the modeling of diffusion processes by GLMM fails to include several important mechanisms that may be involved in diffusion and that the model they deploy is therefore likely to be insufficient. We suggest possible omissions. Nejad provides a comprehensive review of the field and deals with both our review of evidence relating to the validation of GLMM's assumptions and more briefly with our arguments about sufficiency. Rand and Rust focus on the sufficiency argument. We accept some corrections from Nejad where we had misinterpreted GLMM but these do not alter our doubts about this work: that it makes questionable assumptions about WOM and that it is too simple to cover the complexities of diffusion in a social system. Both themes are discussed below.

\begin{abstract}
Assumptions
Advertising produces NWOM

"Advertising, while increasing the number of adopters, indirectly also increases the number of disappointed adopters" (GLMM, p193). We can see that advertising is likely to stimulate some people to adopt products that do not suit them and will thus produce some disappointed adopters because advertising represents the claims of suppliers. Customers recruited via positive word of mouth (PWOM) are likely to make a more informed choice because PWOM lacks commercial bias and may be more related to the needs of receivers. In surveys, Uncles, East, and Lomax (2013) found that ad-recruited customers were less satisfied than referral-recruited customers, but the effect was small. However, Nejad points out that GLMM did not make assumptions about the relative satisfaction of ad-recruited and referral-recruited customers. It seems that the effect of over-advertising comes from a saturation effect. We agree that very high advertising would eventually produce diminishing marginal effects and be inefficient, but GLMM appear to be advising marketers to reduce launch advertising levels below the current norm because of the production of NWOM. It is not clear to us how the saturation effects of advertising produce NWOM. However, East et al. (2015) give evidence on the percentage of NWOM that is triggered primarily by advertising for a service; when the advertising is on the focal product, this is five per cent among those giving NWOM and four per cent among those receiving it. This study also found that three per cent of NWOM (giving and receiving) was triggered by advertising for another brand. From this we argue that advertising does not produce much NWOM and that, if competitor brands are already established, advertising may produce NWOM about these brands which may be advantageous to the focal brand owner.
\end{abstract}

\section{NWOM from dissatisfaction}

"In the modeling approach that we present, negative word of mouth stems from individual customer dissatisfaction" (GLMM, p187). Some NWOM does originate in this way but the 
majority is triggered primarily by other factors; East et al. (2015) found that 26 per cent of the NWOM received about a service was instigated by the communicator's dissatisfaction and 11 per cent by the receiver's dissatisfaction. In the GLMM model, NWOM has a potent effect. This potency might be justified if all NWOM were based on dissatisfaction but it seems harder to justify in other cases where the NWOM is informative advice. Nejad accepts that NWOM has other causes than dissatisfaction and suggests that the GLMM analysis might be based on just PWOM initiated by satisfaction and NWOM initiated by dissatisfaction; however, this would exclude the majority of the WOM occurring in practice, which has effects that should be taken into account. GLMM suggest that NWOM may close down communication about products to sub-groups when those receiving it stop giving PWOM or speak against the product. We question whether NWOM normally has so much effect and see most WOM as advisory with PWOM making purchase more likely and NWOM making it less so, depending on the interpretation and needs of the receiver. To illustrate this, consider the many things that might be said by a user of a new restaurant. Negative comment could cover access, parking, toilets, décor, seating, service, food, range of choice, noise, prices, opening times etc. Sometimes, the negative comments might make a receiver rule out the restaurant but many comments may be seen as minor (e.g. difficult to park, not open on Monday) and a few might be interpreted positively by some receivers (e.g. food very spicy, not child friendly). A smaller impact of NWOM becomes even more plausible when we also consider the next point.

\section{The impact of NWOM relative to PWOM}

"We can assume that the negative word-of-mouth effect is stronger than the positive" (p189). Here GLMM draw on a series of controlled experiments dealing with negativity bias. These studies show that impacts on attitude and cognitive elaboration are generally greater for negative than positive information. The main explanation for this effect is that most information about entities is positive and people form their attitudes on this basis. Thus, negative information differs more from the usually positive attitudes of people than positive information. This makes the negative information more surprising and leaves more room for change. For example, Fiske (1980) studied the effect of negative information about a person on the perception of that person. In this case, negative information had more effect on perception than positive information because the prior attitude was positive.

In contrast, East, Hammond, and Lomax (2008) found that PWOM had more impact on intention to purchase (not attitude) in most of the 19 categories they studied. Their explanation was similar to the negativity bias explanation. They found that the intention to purchase before receiving WOM tended to be below 0.5 so that a larger change was possible in response to PWOM (increasing the probability of purchase) than in response to NWOM (reducing the probability of purchase). This work is supported by Sweeney, Soutar, and Mazzarol (2014). We recognize that there are many studies showing a greater effect of negative experience (e.g. Baumaster, Bratslavsky, and Finkenauer 2001) and a substantial amount of work shows that "losses loom larger than gains" (Kahneman, Knetsch, and Thaler 1991) but this evidence is not specifically on product purchase.

Nejad adds more recent research by Chen, Wang, and Xie (2011) and Nam, Manchanda, and Chintagunta (2010). Both studies provide good evidence that negative information has more impact on behavior than positive information, although Chen et al. find that positive observational learning has an impact when negative observational learning does not. There is clearly much more to be learned about the circumstances that affect the impact of positive and negative advice. For example, remote advice (e.g. from websites or social media) might have somewhat different effects to face-to-face advice and yes-no decisions may differ from one-from-many decisions. In the absence of a comprehensive explanation of 
the differing studies, we see the matter as unclear and likely to be explained better by intensive research in particular areas. The evidence of East et al. (2008) and Sweeney et al. (2014) is relevant to the issue that concerns us since these studies deal with consumers' intention to purchase, which is closer to actual purchase than the attitude or cognition in negativity bias studies. Nejad comments that, if negative information has less effect than GLMM supposed, the impact on a firm's profits will be reduced in their model. This would lessen the hazard of over-advertising.

\section{The ratio of $P W O M$ to $N W O M$}

"There is general agreement in the literature that a dissatisfied customer influences others more than a satisfied one" (GLMM, p187). This relates to the volumes of NWOM and PWOM produced by dissatisfied and satisfied customers rather than the relative impact. In a substantial study using Consumer Satisfaction Index data, Anderson (1998) finds that dissatisfied customers produce more WOM than satisfied customers but he comments that the difference is not large and that, in a sizable proportion of the cases, is probably not significant. Thus, the widely quoted ratios in the region of 2:1 are not supported by Anderson's work. By contrast, an approximately 2:1 ratio was found by Goodman and Newman (2003). EURL argued that the effect of NWOM would depend on its relative volume compared with PWOM but failed to derive a ratio from the assumptions given by GLMM. Nejad shows that a ratio can be obtained from the percentage of disappointed adopters, where the range assumed by GLMM is $5-25 \%$, and the complementary percentages $(95-75 \%)$ of satisfied adopters. If each adopter produces one unit of WOM, these numbers would produce a PWOM to NWOM ratio range of $75 / 25$ to $95 / 5$, or 3 to 19 . We are uneasy about this computation because of the assumed $100 \%$ link between dissatisfaction and NWOM previously discussed. Evidence from surveys on the ratio of PWOM to NWOM comes in at the low end of the 3 to 19 range. East et al. (2007) found a PWOM to NWOM ratio of about 3:1; data from the Keller Fay Group cited in EURL give a ratio of 3.5:1 if mixed conversations are treated as both positive and negative. Our experience with other studies is that $3: 1$ is about average but the ratio varies across categories.

\section{Sufficiency}

The basic mechanism of diffusion is that an adopter sometimes gives PWOM, some of which conscripts new adopters who then repeat the process so that it is similar to the spread of a disease. GLMM's model extends this process by suggesting how NWOM may arrest the spread of information and adoption.

EURL argued that other mechanisms could have a strong effect on diffusion. Advertising may generate PWOM (25\% of PWOM is ad-based according to Keller and Fay, 2012) and we have already noted that advertising could cause NWOM about competitor products as well as the focal brand. In addition, EURL listed saturation effects, decay effects, differential customer retention depending on mode of customer acquisition, reflexive feedback effects whereby the utterance of WOM affects the likelihood of further utterance, and the way in which customers may repeat WOM received from others. All these effects are potentially significant and of practical relevance to advertisers and marketers.

Rand and Rust argue that the emphasis should be on creating a model that is elegantly simple rather than one that attempts to be complete. They point to external shocks such as unusual weather events that disrupt prediction but which ordinarily would not be put into customer-focused diffusion models. We agree. Such events may have a once-off impact, but they are not routinely significant, nor are they of much practical relevance for advertisers and marketers (in the sense they are not actionable). What is needed is the representation of those mechanisms that are interrelated in a system, provided they make a major contribution that is 
of practical relevance to the area being studied. Interrelated processes include WOM after adoption and adoption following receipt of WOM. External shocks are not part of this system. Rand and Rust give the example of the Bass (1969) model, which is elegantly simple and fairly good at predicting outcomes. However, in the Bass model, the internal and external parameters, and the proportion of potential adopters who have adopted, may each cover a range of variables. For example, the proportion of potential adopters who have adopted relates to the product life cycle and is thus often associated with falling prices, quality development and increased distribution. In the individual-level ABM modeling that has been reported to date, the variables do not cover so much, so major mechanisms may be left out.

A related problem in this field is that evidence on the completeness of ABM models is lacking - we do not know whether major mechanisms are left out. One way to check is through outcome validation. A weather forecasting model may be incomplete if it fails to predict the weather with reasonable accuracy. If GLMM had presented evidence of increased NWOM and new product failure with increased ad budgets, they would have provided evidence that their model was useful and possibly complete but they did not offer such outcome validation.

Even without a measure of outcome, specific effects can be investigated as candidates for inclusion in the model. We consider just one here - the transmission of PWOM about products that we own and use (rather than the origination of PWOM following adoption). Most of us can admit to passing on PWOM about products that we already own - this is part of the shared experience of everyday life. These products are interesting to us and new information about them will attract further interest and can easily become the substance of conversations. A feature of this process is that it relies on a network of existing users who can be activated by new information to increase their PWOM and, as a result, produce further adoptions. This mechanism is additional to the growth of adoption via the disease model but we do not know how strong it is and the extent to which a parallel process occurs in the transmission of NWOM. Watts and Dodds (2007) argued that the one-way process in the disease model was an inadequate representation of the diffusion process; an interesting aspect of the transmission of PWOM on a brand by users of that brand is that it partly frees diffusion from the constraint of the disease model because PWOM is propagated within the network of users and is not conditional on new adoption. What this example shows is that there seems to be at least one highly relevant mechanism left out of GLMM's model and, we suggest, this is not an isolated example.

\section{Conclusion}

GLMM's paper is elegantly written and has stimulated debate but we will be surprised if their modeling does not need substantial revision, leading to rather different conclusions. Practitioners should be wary of saturating the market with advertising, but more evidence is needed before we can argue that current ad spending levels at the time of product launch are excessive.

For ABM more generally, researchers would find it easier to engage if the input assumptions were listed in a more accessible way and subjected to more searching validation checks, if model outputs were calibrated and assessed against observed outputs, and if all mechanisms that are significant and relevant were included.

\section{References}

Anderson, E.W. (1998). Customer satisfaction and word of mouth, Journal of Service Research, 1 (1), 5-17.

Bass, F.M. (1969). A new product growth model for consumer durables, Management Science, 15 (5), 215-27. 
Baumeister, R.F., Bratslavsky, E., Finkenauer, K., Vols, K.D. (2001). Bad is stronger than good, Review of General Psychology, 5 (4), 323-370.

East, R., Hammond, K. and Lomax, W. (2008). Measuring the impact of positive and negative word of mouth on brand purchase probability, International Journal of Research in Marketing, 25 (3), 215-224.

East, R., Romaniuk, J. and Lomax, W. (2011). The prediction of brand performance from word-of-mouth and satisfaction measures, The International Journal of Market Research, 53 (3) 327-346.

East, R., Uncles, M., Romaniuk, J. and Dall'Olmo Riley, F. (2015). Factors associated with the production of word of mouth, International Journal of Marketing Research, 57 (3), 439-58.

Fiske, S.T. (1980). Attention and weight in person perception: The impact of negative and extreme behavior, Journal of Personality and Social Psychology, 38 (6), 889-906.

Goldenberg, J., Libai, B., Moldovan, S., and Muller, E. (2007). The NPV of bad news, International Journal of Research in Marketing, 24 (3), 186-200.

Goodman, J. and Newman, S. (2003). Understanding Customer Behavior and Complaints. TARP (Technical Assistance Research Programs), available via www.asq.org.

Kahneman, D., Knetsch, J. and Thaler, R. (1991). Anomalies: The endowment effect, loss aversion, and status quo bias, Journal of Economic Perspectives, 5 (1), 193-206.

Keller E. Fay, B (2012). The Face-to-Face Book. Free Press: New York.

Rand, W. and Rust, R.T. (2011). Agent-based modeling in marketing: Guidelines for rigor, International Journal of Research in Marketing, 28 (3), 181-93.

Sweeney, J., Soutar, G. and Mazzarol, T. (2014). Factors enhancing word-of-mouth influence: Positive and negative service-related messages, European Journal of Marketing, 48 (1/2), 336-59.

Uncles, M., East, R. and Lomax, W. (2013). Good customers: The value of customers by mode of acquisition, Australasian Marketing Journal, 21 (2), 119-125.

Watts, D.J. and P.S. Dodds (2007). Influentials, networks, and public opinion formation, Journal of Consumer Research, 34 (4), 441-58, (2007). 